\title{
Comparing Ecological Site Descriptions to Habitat Characteristics Influencing Greater Sage-Grouse Nest Site Occurrence and Success
}

\author{
Kevin E. Doherty, ${ }^{1}$ Jeffrey L. Beck, ${ }^{2}$ and David E. Naugle ${ }^{3}$ \\ ${ }^{1}$ Graduate Research Assistant and ${ }^{3}$ Professor, Wildlife Biology Program, University of Montana, Missoula, MT 59812, USA; and ${ }^{2}$ Assistant Professor, \\ Department of Renewable Resources, University of Wyoming, Laramie, WY 82071, USA.
}

\begin{abstract}
We used 119 greater sage-grouse (Centrocercus urophasianus) nests located in the Powder River Basin of northeastern Wyoming during 2004-2007 to assess the ability of US Department of Agriculture-Natural Resource Conservation Service (USDA-NRCS) ecological site descriptions (ESDs) to predict nest occurrence and success. We used nesting data from a regional study in the Powder River Basin that documented effects of local and landscape scale habitat characteristics on nest occurrence and success. We compared ESD metrics to these predictive local and landscape habitat variables where NRCS ESD field surveys overlapped our regional nest data set. We specifically asked three questions: 1) Are ESDs useful in predicting sage-grouse nest site occurrence and success as a univariate explanatory variable? 2) Can ESD information refine predictions of local scale nest site occurrence and success models? 3) Can ESD information refine landscape scale nest site occurrence models by serving as a surrogate for local scale information that cannot be mapped in a geographic information system (GIS)? Our results demonstrated that all models using ESD information were within \pm 2 Akaike's Information Criterion points of a constant only model (i.e., null model) for local-scale data, or a baseline model where local- and landscape-scale habitat metrics were held constant while allowing ESD models to compete for remaining variation. No ESD metrics were statistically significant at the $95 \%$ level $(P<0.05)$, although some were significant at the $80-90 \%$ level $(P=0.09-0.14)$. Our study does not support the use of ESDs to predict habitat use or base sage-grouse management decisions in the Powder River Basin, but in some instances the refutation was weak. Local and landscape based habitat metrics showed high discrimination between null models with highly significant relationships on the subset data.
\end{abstract}

\section{Resumen}

Utilizamos 119 nidos de urogallo (Centrocercus urophasianus) localizados en la cuenca del río Powder en el noreste de Wyoming durante 2004-2007 para evaluar la capacidad de la descripción ecológica del sitio (ESDs) usado por el Departamento de Agricultura y el Servicio de Conservación de los Recursos Naturales (USDA-NRCS) de los Estados Unidos para predecir la ocurrencia y éxito de los nidos de esta especie. Utilizamos los datos de anidación de un estudio regional en la cuenca del rio Powder que documentaron los efectos locales y las características del hábitat a escala de sitio en la presencia y éxito de los nidos. Utilizamos las medidas de ESD para estas variables de predicción a nivel local y del hábitat donde los estudios de campo de NRCS coinciden con nuestro conjunto de datos nidos. Tuvimos 3 preguntas específicas: 1) ¿ Son EDSs de utilidad para predecir la ocurrencia y éxito de los nidos de urogallo como variable explicativa invariada? 2) ¿Puede la información de ESD mejorar las predicciones de los modelos de la ocurrencia y éxito de los sitios de los nidos a escala local? 3) ¿Puede la información mejorar a nivel de hábitat los modelos de aparición de nidos funcionando como un sustituto para obtener información a escala local que no puede ser registrada en sistema de información geográfica (GIS)? Nuestros resultados demuestran que todos los modelos que utilizaron la información de ESD estuvieron entre \pm 2 puntos de AIC de un modelo único constante (es decir modelo nulo) para los datos de escala local, o un modelo de referencia donde las métricas de hábitat de la escala local y de paisaje se mantienen constantes permitiendo a los modelos de ESD competir por la variación restante. Ninguna de las métricas de ESD fueron estadísticamente significativas a un nivel de $95 \%(P<0.05)$, aunque algunas fueron significativas a un nivel de $80-90 \%(P=0.09-0.14)$. Nuestro estudio no apoya el uso de ESDs en las decisiones de manejo en la cuenca del rio Powder para predecir el uso del hábitat por el urogallo, pero en algunas ocasiones la refutación fue débil. Las métricas utilizadas a nivel local y del hábitat presentaron una gran segregación entre los modelos nulos con una relación muy significativa entre el subconjunto de datos.

Key Words: Centrocercus urophasianus, landscape-scale habitat characteristics, local-scale habitat characteristics, nesting ecology, wildlife habitat assessment

Research was supported in part by the Wyoming Wildlife and Natural Resource Trust Fund.

Kevin E. Doherty was at the University of Montana, Missoula, MT, USA, when nest data and habitat metrics were collected and analyzed; he was a senior ecologist at Audubon Wyoming, Laramie, WY 82072, USA, when nesting information was compared to ESD information.

Current address: Kevin E. Doherty, Prairie Pothole Joint Venture Science Coordinator, USDI Fish and Wildlife Service, Bismarck, ND 58501, USA.

Correspondence: Jeffrey L. Beck, Dept of Renewable Resources, University of Wyoming, Dept 3354, 1000 E. University Ave, Laramie, WY 82071, USA. Email: jlbeck@uwyo.edu

\section{INTRODUCTION}

The US Department of Agriculture-Natural Resources Conservation Service (USDA-NRCS) has developed a land classification, management, and monitoring system focused on ecological sites. "An ecological site, as defined for rangeland, is a distinctive kind of land with specific physical characteristics that differs from other kinds of land in its ability to produce a 
distinctive kind and amount of vegetation (USDA-NRCS 2006b:3.1-1)." The USDA-NRCS ecological site system is nested within a hierarchical classification of broad-scale land resource regions (LRRs), major land resource areas (MLRAs), and fine-scale ecological sites (USDA-NRCS 2006a). LRRs are largely based on agronomic production capabilities tied to regional soils maps (USDA-NRCS 2006a). Within LRRs, geographic areas with similar elevation, topography, geology, climate, water, soils, biological resources, and land uses characterize MLRAs (USDA-NRCS 2006a; Cagney et al. 2010). Ecological site descriptions (ESDs) are based on soils information that is grouped climatically within MLRAs; consequently, ESDs provide managers with tools to base vegetative management, restoration, performance criteria, and risk assessment and monitoring decisions (Herrick et al. 2006). Most rangeland ESDs are based on previous range site descriptions (RSDs); whereas RSDs provided descriptive information about livestock production and wildlife habitat (Brown et al. 2002), ESDs provide more information on ecological processes and dynamics through incorporating state and transition models (Herrick et al. 2006). Consequently, the utility of ESDs as they are currently devised to interpret wildlife habitat values may be limited. In addition, the spatial scale of ecological sites may or may not reflect the scales required by various wildlife species in selecting habitats (Brown et al. 2002). Here we evaluate the relative ability of ESDs to predict, refine, and serve as surrogates for local and landscape information known to be important to greater sage-grouse (Centrocercus urophasianus; hereafter sage-grouse) nest site occurrence (Doherty et al. 2010a) and nest success (Doherty, unpublished data).

Human impacts within the last century have resulted in loss and degradation of sagebrush (Artemisia spp. L.) ecosystems in western North America (Knick et al. 2003). Greater sagegrouse are a focal species of high conservation concern in the sagebrush ecosystem that have been petitioned for listing under the Endangered Species Act of 1973 and currently have a warranted, but precluded, status under the Endangered Species Act (USDI-FWS 2010). Sage-grouse core regions, a recent framework for conservation planning, showed that by selecting highest density areas first, managers could define core regions that contain $25 \%, 50 \%, 75 \%$, and $100 \%$ of the breeding population within $5 \%, 12 \%, 30 \%$, and $60 \%$ of the eastern sage-grouse range, respectively (Doherty et al. 2011). Identification and mapping of core-regions provided the mechanism for assessing trade-offs between biological value and anthropogenic risk to deliver the greatest conservation benefit to populations (Abbitt et al. 2000; Balmford et al. 2001; Wilson et al. 2005; Doherty et al. 2011). Core regions represent a proactive attempt to identify and maintain a viable set of populations before the opportunity to do so is lost and can direct conservation to areas where actions will have the largest benefit to populations. As such, the USDA-NRCS intend to use sage-grouse core region population models to prioritize private landowner enrollment in conservation programs (environmental quality incentive program, grassland reserve program, wetland reserve program, and wildlife habitat incentive program) designed to enhance sage-grouse habitat.

We evaluated ESD information collected by the USDANRCS to evaluate whether existing ESD data collected for management purposes could be used to refine sage-grouse management beyond existing core region models. We compared ESD information to local (i.e., field vegetation plots) and landscape (i.e., geographic information system [GIS]-derived) habitat characteristics known to be important to nest site occurrence and success. We examined three questions relating to the utility of using USDA-NRCS ESD metrics for sagegrouse management: 1) Are ESDs useful in predicting sagegrouse nest site occurrence and success as a univariate explanatory variable? 2) Can ESD information refine predictions of local scale nest site occurrence and success models? 3) Can ESD information refine landscape scale nest site occurrence models by serving as a surrogate for local scale information that cannot be mapped in a GIS?

\section{STUDY AREA}

Our study area was located in the Powder River Basin and encompassed portions of Johnson County, Wyoming. Shrubsteppe habitat was dominated by Wyoming big sagebrush (Artemisia tridentata Nutt. ssp. wyomingensis Beetle \& Young) with an understory of native and non-native grasses including bluebunch wheatgrass (Pseudoroegneria spicata [Pursh] A. Löve), blue grama (Bouteloua gracilis [Willd. ex Kunth] Lag. ex Griffiths), cheatgrass (Bromus tectorum L.), crested wheatgrass (Agropyron cristatum [L.] Gaertn.), Japanese brome (Bromus japonicus Thunb.), prairie junegrass (Koeleria macrantha [Ledeb.] Schult.), and western wheatgrass (Pascopyrum smithii [Rydb.] A. Löve). Silver sagebrush (Artemisia cana Pursh ssp. cana) was also present in drainages. Limited amounts of Rocky mountain juniper (Juniperus scopulorum Sarg.) and ponderosa pine (Pinus ponderosa C. Lawson) occurred in draws. Land use was dominated by cattle ranching, and only $4 \%$ of the landscape consisted of dry-land or irrigated agriculture. Doherty (2008) provides a detailed description of the study area.

\section{METHODS}

\section{Existing Sage-grouse Data}

To evaluate USDA-NRCS ESD information, we used an existing sage-grouse nest data set from prior research on habitat effects on nest site occurrence and success. We used 527 locations from 2004 to 2007 to build and validate the models of nest occurrence (Doherty et al. 2010a) and success (Doherty, unpublished data). Of these 527 locations, 223 nests and 223 available locations were from the Johnson County study site in Wyoming near USDA-NRCS ESD surveys. We were able to determine nest success status for 209 of these nests (Table 1). We randomly selected available nesting locations from a spatial Poisson distribution (Beyer 2004) proportional to the number of nests within a study area and year. We constrained available locations to within $5 \mathrm{~km}$ of the lek of capture or the lek closest to the capture location for female sage-grouse (Holloran and Anderson 2005) to avoid sampling large areas of conifer forest. The $5-\mathrm{km}$ radius encompassed $79 \%$ of all nests in our study (Doherty et al. 2010a). Within the Johnson County study sites, 119 nest locations and 134 available locations were located 
Table 1. Mean \pm SE for important local-scale predictors of greater sage-grouse nest occurrence and success measured along 2 , $15 \times 1 \mathrm{~m}$ transects centered on nests or random, available locations, Johnson County, Wyoming, USA, 2004-2007. Data are reported at all sites to compare to those that occurred on sites where ecological site descriptions were available. Numbers in parentheses are samples sizes.

\begin{tabular}{|c|c|c|c|c|}
\hline \multirow[b]{2}{*}{ Nest occurrence } & \multicolumn{2}{|c|}{ University of Montana Johnson County study sites } & \multicolumn{2}{|c|}{ NRCS-ESD ${ }^{1}$ Sites in Johnson County } \\
\hline & Used (223) & Available (223) & Used (119) & Available (134) \\
\hline Canopy cover $(\%)^{2}$ & $18.8 \pm 0.6$ & $13.1 \pm 0.7$ & $20.5 \pm 0.8$ & $14.6 \pm 0.9$ \\
\hline Robel pole $(\mathrm{cm})$ & $15.5 \pm 0.5$ & $10.4 \pm 0.5$ & $16.0 \pm 0.7$ & $11.4 \pm 0.7$ \\
\hline Nest success & Successful (156) & Unsuccessful (53) & Successful (80) & Unsuccessful (38) \\
\hline Grass height $(\mathrm{cm})$ & $20.6 \pm 0.6$ & $15.9 \pm 1.0$ & $21.5 \pm 0.8$ & $15.3 \pm 1.0$ \\
\hline
\end{tabular}

${ }^{1}$ NRCS, Natural Resource Conservation Service; ESD, ecological site description.

${ }^{2}$ Quadratic term for sagebrush canopy cover within $15 \mathrm{~m}$ of nest or available locations (Doherty et al. 2010a).

within areas where the USDA-NRCS conducted ESD surveys (Table 1). We used all nest and available locations for the nest site occurrence analyses. For nest success analyses, we used 118 nest locations for model selection and parameter estimation because we could not determine nest success status for 1 of the 119 nests. Sagebrush canopy cover and average Robel pole readings were similar at nests and randomly available locations with NRCS-ESD information compared to the larger sample of nests and available locations in Johnson County, Wyoming (Table 1). Grass height at successful and unsuccessful nests was similar at locations with NRCS-ESD information compared to the larger sample of successful and unsuccessful nests in Johnson County, Wyoming (Table 1).

\section{Local Scale}

We defined habitat variables quantified from field vegetation plots as "local-scale" habitat features. We used published protocols (Connelly et al. 2003) to quantify local vegetative features known to influence habitat selection within $\leq 15 \mathrm{~m}$ of nest and available points (e.g., Connelly et al. 2000; Hagen et al. 2007). Local-scale habitat variables included shrub canopy cover, shrub density, shrub height, nest shrub height, visual obstruction (Robel et al. 1970), and grass height (e.g., Connelly et al. 2000; Hagen et al. 2007). Further details are available in Doherty et al. (2010a) or Doherty (2008). The final local-scale model for nest site occurrence from Doherty et al. (2010a) included the average Robel pole value and a quadratic term for sagebrush canopy cover. Doherty (unpublished data) found that average grass height within $15 \mathrm{~m}$ of the nest was the only local scale variable strongly associated with daily survival rates of nests. Average Robel value and a quadratic term for sagebrush canopy cover were held constant when asking if ESD information could refine predictions of local scale nest site occurrence models. The average grass height at a local scale was held constant when testing the effectiveness of ESD information as a predictor of local scale nest success.

\section{Landscape Scale}

We defined landscape scale features as those we quantified in a GIS. We quantified characteristics of vegetation and topography around nest and available locations in a GIS to evaluate habitat selection at four landscape scales $(100 \mathrm{~m}, 300 \mathrm{~m}$, $1500 \mathrm{~m}$, and $3000 \mathrm{~m}$ ). We calculated percent area of grassland, high density sagebrush, conifer, sparse vegetation, and tilled agriculture by summing the number of pixels at each scale. We used topography to calculate ruggedness of the landscape as the standard deviation of a 30-m resolution digital elevation model (Doherty 2008). For nest site occurrence, the landscape model included percent grassland within $100 \mathrm{~m}$, a quadratic term for percent high density sagebrush within $100 \mathrm{~m}$, terrain roughness within $100 \mathrm{~m}$, percent conifer within $100 \mathrm{~m}$, and percent riparian habitat within $350 \mathrm{~m}$ (Doherty et al. 2010a). For nest success, no landscape variables were found to be predictive when included with a study area blocking variable. We therefore did not compare landscape scale habitat measured through satellite imagery to ESD information for nest success.

We held the top landscape scale habitat features constant when assessing if ESD information could refine landscape scale nest site occurrence models by serving as a surrogate for local scale information that cannot be mapped in a GIS.

\section{Local and Landscape Habitat Variables From Prior Analyses}

We used habitat variables identified from the best models of nest occurrence (Doherty et al. 2010a) and nest success (Doherty, unpublished data) as baseline information to compare ESDs' ability to predict sage-grouse nest site occurrence and success. Doherty et al. (unpublished data) screened the variable sets in Doherty et al. (2010a) and found that average grass height within $15 \mathrm{~m}$ of the nest was the only local scale variable that was strongly associated with daily survival rates of nests. All variables from either local or landscape scales in the top models from Doherty et al. (2010a) and Doherty (unpublished data) were held constant for questions 2 and 3. In prior analyses of sage-grouse nest site occurrence and success, either local or local and landscape habitat variables were highly predictive and discriminated between constant only (null or no predictor variables) models.

\section{NRCS Ecological Site Descriptions}

We evaluated ESD information collected by rangeland conservationists employed by the US Department of Interior-Bureau of Land Management and USDA-NRCS to evaluate whether existing ESD data collected for management purposes could be used to refine suitable sage-grouse nesting habitat predictions. These ESD evaluations were conducted within MLRA 58BNorthern Rolling High Plains, Southern Part, covering approximately $49915 \mathrm{~km}^{2}$ in Wyoming $(95 \%)$ and Montana $(5 \%$; 
USDA-NRCS 2006a). Detailed protocols for inventorying and monitoring grazing land resources for ESD classifications are available in Chapter 4 of the National Range and Pasture Handbook (USDA-NRCS 2006b). Following these established protocols, a rangeland conservationist first determined ESD ecotypes based upon slope and soil information. Once ecotypes were identified, a rangeland conservationist confirmed polygon boundaries of unique ecotypes, which were delineated from $1 \mathrm{~m}$ USDA-National Agriculture Imagery Program imagery. Within defined polygon areas, the rangeland conservationist then collected information on species composition by vegetative functional group (grasses, shrubs, and forbs) and indicators of rangeland quality including bare ground, amount of litter, annual grasses, and perennial grasses; these data were collected according to established protocols in Chapter 3 of the National Range and Pasture Handbook (USDA-NRCS 2006b). Local scale information collected within an ecotype polygon boundary was summarized into a similarity index (SI) class for each ESD ranging from 0 to 100, with 0 representing a severely degraded area.

\section{Capture and Radio-Monitoring Sage-Grouse}

We captured sage-grouse in rocket-nets and walk-in traps (Giesen et al. 1982) and by spotlighting (Wakkinen et al. 1992) between March and April 2004-2007. We aged females and fitted them with a 21.6-g necklace style radio collar (model A4060, Advanced Telemetry Systems, Isanti, MN). We relocated sage-grouse to monitor nests by ground based radio-tracking throughout the breeding season. Sage-grouse nests were monitored two to three times per week from first incubation to determine the locations of successful or unsuccessful nests. We considered a nest successful if $\geq 1$ egg hatched, which we identified by detached eggshell membranes (Wallestad and Pyrah 1974). Unsuccessful nests were depredated, naturally abandoned, or failed due to the depredation of nesting females or for unknown reasons. We searched for broods during $\geq 3$ visits to evaluate fate of nests thought to be depredated close to their predicted hatching date or whose fate was unclear. We used a Global Positioning System (GPS) receiver to record nest locations after they had hatched or failed. Locations were collected when GPS unit (Garmin Model eTrex Legend, Garmin International, New York, NY) error estimates were $<7 \mathrm{~m}$.

\section{Statistical Analyses}

We employed logistic regression with used and available locations for model selection and resource selection function model parameter estimates for nest occurrence (Boyce et al. 2002; Manly et al. 2002; Johnson et al. 2006). We also used logistic regression to compare successful to unsuccessful nest locations within our study area.

We conducted separate nest site occurrence and nest success analyses for each of our three research questions. For questions 2 and 3, we held local or landscape habitat variables identified in previous research constant during data screening and model selection. We first screened ESD variables and removed those with $P>0.25$ (Table 2) following the analysis paradigm of Aldridge and Boyce (2007). No ESD variables brought forward in the analyses were highly correlated $(r \geq 10.71)$. Secondly, we used all possible subsets of ESD variables that passed screening
Table 2. Descriptions and univariate variable screening of 13 of 23 ecological site descriptions quantified by the US Department of Agriculture-Natural Resource Conservation Service in the Powder River Basin, Wyoming, USA, in areas where sage-grouse nest occurrence and success analyses also occurred, summers 2004-2007. For each ecological site description variable, the beta coefficient $(\beta)$ and associated $P$-value are presented.

\begin{tabular}{|c|c|c|c|}
\hline Variable & Description & Occurrence & Success \\
\hline$\beta$ (Eco_CY) & Clayey soil type & 0.008 & -0.010 \\
\hline$P($ Eco_CY $)$ & & $0.14^{*}$ & $0.17^{*}$ \\
\hline Eco_CYOV & Clayey overflow & $N A^{1}$ & $N A^{3}$ \\
\hline Eco_LL & Lowland soil type & $N A^{2}$ & $N A^{4,5}$ \\
\hline$\beta$ (Eco_LY) & Loamy soil type & -0.004 & 0.004 \\
\hline$P($ Eco_LY $)$ & & 0.26 & 0.43 \\
\hline$\beta$ (Eco_OV) & Water overflow area & 0.028 & 0.003 \\
\hline$P($ Eco_OV) & & 0.36 & 0.95 \\
\hline$\beta($ Eco_OW) & Open water & -0.103 & $N A^{4}$ \\
\hline$P($ Eco_OW $)$ & & 0.41 & \\
\hline$\beta$ (Eco_SW) & Shallow & 0.017 & 0.036 \\
\hline$P$ (Eco_SW) & & 0.47 & 0.38 \\
\hline$\beta$ (Eco_SWCY) & Shallow clayey soils & 0.011 & -0.008 \\
\hline$P$ (Eco_SWCY) & & $0.12^{*}$ & 0.36 \\
\hline$\beta$ (Eco_SWLY) & Shallow loamy soils & -0.001 & 0.002 \\
\hline$P$ (Eco_SWLY) & & 0.82 & 0.85 \\
\hline$\beta$ (Eco_SWSY) & Shallow sandy soils & -0.026 & -0.001 \\
\hline$P$ (Eco_SWSY) & & $0.21^{*}$ & 0.97 \\
\hline$\beta$ (Eco_SY) & Sandy soils & -0.020 & $N A^{3}$ \\
\hline$P$ (Eco_SY) & & 0.30 & \\
\hline$\beta$ (Eco_VIII) & Nonirrigated & -0.024 & -0.002 \\
\hline$P$ (Eco_VIII) & & 0.51 & 0.98 \\
\hline$\beta$ (Eco_VS) & Very shallow soil area & -0.007 & 0.015 \\
\hline$P$ (Eco_VS) & & 0.61 & 0.52 \\
\hline$\beta$ (Site Index) & Independent reference to & -0.011 & 0.038 \\
\hline$P$ (Site index $)$ & condition of ecological sites & 0.43 & $0.10^{*}$ \\
\hline
\end{tabular}

*Variables with $P<0.25$ that passed the data screening criteria and were subsequently used in analyses.

${ }^{1}$ Variable predicted nest occurrence perfectly because it was extremely rare and only found at $0.83 \%$ of nest sites.

${ }^{2}$ Variable predicted nonoccurrence for sage-grouse nests perfectly because it was extremely rare and only found at $0.74 \%$ of available sites.

${ }^{3}$ Variable dropped because of colinearity, no unsuccessful nests, and only accounted for $<0.02 \%$ of successful nests.

${ }^{4}$ No nests located within these ecological site descriptions for nest success analyses. ${ }^{5} \mathrm{NA}$, not applicable.

for each of the three questions. We assessed model selection and inference strength using Akaike's Information Criterion (AIC) and the Bayesian Information Criterion (BIC), while simultaneously assessing beta coefficients and measures of significance. We investigated AIC and BIC, as well as beta coefficients $(\beta)$ and $P$-values, because all metrics provide useful information on model selection and inference strength. We ranked models via AIC for presentation of results (Tables 2-4), but included BIC to show bounds of model selection using different criterion. AIC and BIC metrics are similar and use the same base equation of $-2 \cdot \ln ($ likelihood) to assess model fit (Burnham and Anderson 2002; Stata 2007). AIC and BIC penalty terms differ in that AIC adds $(2 \cdot k)$ to the results of the base equation above where BIC adds $(\ln [\mathrm{N}] \cdot k)$, where 
Table 3. Greater sage-grouse nest occurrence using ecological site descriptions without other local or landscape information in the Powder River Basin, Wyoming, USA, summers 2004-2007. Models are ordered by Akaike's Information Criterion (AIC) scores, and no models with AIC scores $<2.0$ points from the constant only model are shown. Blank model coefficients indicate that the variable was not included in that model set. Coefficients $(\beta)$ were generated from logistic regression. P-values for each coefficient are reported in the next row.

\begin{tabular}{|c|c|c|c|c|c|c|c|}
\hline \multirow[b]{2}{*}{ Variable } & \multicolumn{7}{|c|}{ Model } \\
\hline & 1 & 2 & 3 & 4 & 5 & 6 & $7^{1}$ \\
\hline$\beta$ (Eco_swsy) & - & -0.023 & - & - & -0.024 & -0.026 & - \\
\hline$P$ (Eco_swsy) & - & 0.24 & - & - & 0.23 & 0.21 & - \\
\hline$\beta$ (Eco_swcy) & 0.011 & 0.010 & - & 0.010 & - & - & - \\
\hline$P$ (Eco_swcy) & 0.12 & 0.14 & - & 0.17 & - & - & - \\
\hline$\beta$ (Eco_cy) & - & - & 0.007 & 0.007 & 0.007 & - & - \\
\hline$P$ (Eco_cy) & - & - & 0.14 & 0.20 & 0.16 & - & - \\
\hline$\beta$ (Constant) & -0.190 & -0.14 & -0.180 & -0.24 & -0.132 & -0.065 & -0.110 \\
\hline$P$ (Constant) & - & 0.31 & 0.18 & 0.09 & 0.34 & 0.62 & 0.38 \\
\hline AIC & 352.8 & 353.0 & 353.1 & 353.1 & 353.3 & 353.3 & 353.3 \\
\hline $\mathrm{BIC}$ & 359.9 & 363.6 & 360.2 & 363.8 & 363.9 & 360.4 & 356.9 \\
\hline
\end{tabular}

${ }^{1}$ Denotes Bayesian Information Criterion (BIC) best model that included no variables (i.e., a null model).

$k=$ number of parameters and $N=$ number of observations (Burnham and Anderson 2002). In practice, the differences in penalty terms result in AIC being more inclusive and BIC selecting more parsimonious models. In all tables we present $\beta$ coefficients and $P$-values so readers can assess effect sizes for variables in top models.

\section{RESULTS}

Univariate screening of ESD variables selected three variables for nest site occurrence and two variables for nest success (Table 2). For nest site occurrence, we used clayey (Eco_cy), shallow clayey (Eco_swcy), and shallow sandy (Eco_swsy) ecological sites. We used clayey (Eco_cy) ecological sites and site index scores (SI) for nest success (Table 2).

Table 4. Greater sage-grouse nest success using ecological site descriptions without other local or landscape information in the Powder River Basin, Wyoming, USA, summers 2004-2007. Models are ordered by Akaike's Information Criterion (AIC) scores, and no models with AIC scores $<2.0$ points from the constant only model are shown. Blank model coefficients indicate that the variable was not included in that model set. Coefficients $(\beta)$ were generated from logistic regression. $P$-values for each coefficient are reported in the following row.

\begin{tabular}{lcccc}
\hline & \multicolumn{5}{c}{ Model } \\
\cline { 2 - 5 } Variable & 1 & 2 & $3^{1}$ & 4 \\
\hline$\beta$ (Site Index) & 0.038 & 0.037 & - & - \\
$P$ (Site Index) & 0.10 & 0.11 & - & - \\
$\beta$ (Eco_cy) & - & -0.010 & - & -0.010 \\
$P$ (Eco_cy) & - & 0.19 & - & 0.17 \\
$\beta$ (Constant) & -1.361 & -1.196 & 0.718 & 0.841 \\
$P$ (Constant) & 0.28 & 0.35 & $<0.001$ & $<0.001$ \\
AIC & 151.7 & 152.0 & 152.5 & 152.7 \\
BIC & 157.3 & 160.3 & 155.3 & 158.3 \\
\hline
\end{tabular}

${ }^{1}$ Denotes Bayesian Information Criterion (BIC) best model that included no variables (i.e., a null model).

\section{Question 1: Can ESDs Predict Sage-Grouse Nest Occurrence and Success?}

We found that ESD information was not an effective predictor of sage-grouse nest site occurrence or success in the absence of other local or landscape scale habitat information. In both analyses refutation showed uncertainty (Table 3). We found that the Eco_swcy ecological site was the best model of nest site occurrence (Table 3). Parameter estimates showed that Eco_swcy was positively associated with nest site occurrence ( $\beta=0.011)$, but estimates were not statistically significant. The Eco_swcy model was within 1.0 AIC point of a constant only model that included no predictor variables, which is a sign of poor model performance. BIC model selection criterion ranked the constant only model as best and it was 3.0 points better than Eco_swcy (Table 3). We found that SI was also positively associated with the locations of successful nest sites in the Powder River Basin $(\beta=0.038, P=0.10$; Table 4). Again, SI was within 1.0 AIC point of a constant only model and BIC criterion selected the constant only model as the top model.

\section{Question 2: Can ESDs Refine Local-Scale Predictions of Nest Occurrence and Success?}

We found that ESD information did not refine predictions of local scale habitat models of nest site occurrence or success; however, refutation also showed uncertainty. When we held the average grass height within $15 \mathrm{~m}$ of a nest constant, three variables passed screening (Eco_cy, Eco_ly, and Eco_swcy). When we used AIC, a model that contained Eco_swcy and Eco_cy was the best model (Table 5). Both ESD ecotypes showed a positive effect on nest site occurrence but had nonsignificant coefficients (Table 5). The top model was 1.3 AIC points better than a constant only model while holding local scale habitat constant (i.e., baseline model). BIC model selection identified the baseline model as the top model (Table 5). For nest success, inclusion of ESD variables did not improve model fit using either AIC or BIC. However, the inclusion of the average grass height at a local scale was 31.0 AIC or 28.4 BIC points better than a constant only (i.e., no variables) model. Grass height effectively discriminated between successful and unsuccessful nest locations on this data 
Table 5. Ecological site descriptions effects on greater sage-grouse nest site occurrence in the Powder River Basin, Wyoming, USA, summers 2004-2007, while holding baseline models from Doherty et al. (2010a) constant. We held local scale habitat variables (average Robel pole value and a quadratic term for sagebrush canopy cover) constant in models 1-4 to force ecological site description models to compete for remaining statistical variation. Models are ordered by Akaike's Information Criterion (AIC) scores, and no models with AIC scores $<2.0$ points from the constant only model are shown. Blank model coefficients indicate that the variable was not included in that model set. Coefficients $(\beta)$ were generated from logistic regression. $P$-values for each coefficient are reported in the following row.

\begin{tabular}{lllll}
\hline & \multicolumn{4}{c}{ Model } \\
\cline { 2 - 5 } Variable & 1 & 2 & 3 & $4^{1}$ \\
\hline$\beta$ (Eco_swcy) & 0.012 & 0.013 & - & - \\
$P$ (Eco_swcy) & 0.14 & 0.09 & - & - \\
$\beta$ (Eco_cy) & 0.008 & - & 0.009 & - \\
$P$ (Eco_cy) & 0.14 & - & 0.09 & - \\
$\beta$ (Constant) & -2.750 & -2.670 & -2.650 & -2.540 \\
$P$ (Constant) & $<0.01$ & $<0.01$ & $<0.01$ & $<0.01$ \\
AIC & 318.9 & 319.2 & 319.3 & 320.2 \\
BIC & 340.2 & 336.9 & 337.0 & 334.3 \\
\hline
\end{tabular}

${ }^{1}$ Denotes Bayesian Information Criterion (BIC) best model that included no variables (i.e., a null model).

set. If SI was included with local scale grass height, it was 1.3 AIC or 4.0 BIC points worse than just grass height alone. Further, variation increased if SI was included with grass height (SI $=0.038$, SE 0.23, $P=0.10$; Model 1 [Table 4] vs. 0.021, SE $0.03, P=0.42$ with grass height). Locations of successful nests were not associated with SI when included with grass height.

\section{Question 3: Can ESDs Refine Landscape-Scale Nest Site Occurrence Models?}

We found clear evidence that ESD information as collected by the USDA-NRCS does not refine landscape scale habitat selection models by serving as a surrogate for local scale information that cannot be currently mapped in a GIS. For nest site occurrence, all ESD variables had $P>0.25$ when included with the best landscape scale habitat model identified in Doherty et al. (2010a). The exception was Eco_cy $(P=0.19)$; including Eco_cy resulted in a model fit of 0.9 AIC or 3.7 BIC points worse than the null model. ESD information that we evaluated does not appear to be a substitute for local scale habitat information that cannot be currently mapped in a GIS.

\section{DISCUSSION}

Local and landscape habitat variables identified in prior research in the Powder River Basin (Doherty et al. 2010a; Doherty, unpublished data) again predicted sage-grouse nest site occurrence and success in our analyses. In all cases local or landscape models discriminated between null models and were between 12.5 and 33.1 AIC points better than constant only models (Doherty et al. 2010a; Doherty, unpublished data). However, in evaluating questions 1-3 there was substantial uncertainty in model selection and inferential strength for all ESD metrics. For question 1 our results show that the best model of ESD information for occurrence and success was within \pm 2 AIC points of the constant only model. We found the same pattern for questions 2 and 3 where we held local or landscape scale habitat metrics constant while allowing ESD models to compete for remaining variation. In these cases best ESD models were \pm 2 AIC points of models that included no ESD information. BIC model selection excluded the use of all ESD information for each of the three questions and in no instances were ESD metrics statistically significant $(P>0.05)$. Our analyses highlight uncertainty in the utility of ESD information as currently collected by the NRCS as a basis for making sage-grouse management decisions.

Our study design was opportunistic and made use of an existing data set on sage-grouse locations when they overlapped with USDA-NRCS ESD information and may have not tested the full utility of ESD information. First, our sage-grouse data set sampled 13 of 23 ESD types in the Powder River Basin where sage-grouse and ESD datasets overlapped. At larger study area extents, it is possible that the predictive strength of ESD information would increase. This is because the likelihood of sampling available locations with ESD types that generally support nonsagebrush habitat would increase. Having nonhabitat or nonselected habitat types in the available sample is critical in resource selection function modeling (Manly et al. 2002). For example, saline upland ecotypes generally result in saltbush (Atriplex spp.) and greasewood (Sarcobatus vermiculatus) dominated stands (Cagney et al. 2010), and occurrence models should detect negative associations of sage-grouse with these habitats. Second, ESD information from the USDANRCS was evaluated in the year prior to ranch enrollment in the Environmental Quality Incentive Program. However ESD information may need to be evaluated on an annual basis or at least in years with varying precipitation. All local scale vegetation data from Doherty et al. (2010a) and Doherty (unpublished data) were collected within $2 \mathrm{wk}$ of nest hatch at successful locations or within $2 \mathrm{wk}$ of the predicted hatch date at unsuccessful nest locations. For example, during 2004, drought was so severe that most forbs were not expressed and most native grasses did not seed. Because of the differences in vegetation during drought and normal-to-above average precipitation years, ESD "snapshots" may not be tracking the biological and vegetative cues that drive annual variations in sage-grouse nest success and occurrence. Third, how the NRCS collected ESD information in the field may need to be refined for research purposes or if used as a paradigm for sage-grouse management. However, it is important to note that our study evaluated ESD information in the format currently used by NRCS and was conducted in one of the remaining sage-grouse population centers in the Powder River Basin.

While no ESD information was significant or strongly supported or refuted in model selection, the same nonsignificant biological effects agree with what managers would expect. Positive associations of higher site index values to successful nest locations are supported in the published sage-grouse literature. A meta-analysis of sage-grouse nesting habitat studies indicated sagebrush cover $(\% ; n=19$, mean $=21.7$ [95\% CI: 19.9-23.9]) and grass height (cm; $n=20$, mean $=19.8$ [95\% CI: $17.4-22.2]$ ) were greater at nest sites 
than random sites (Hagen et al. 2007). Although measured effects vary, the structure of grasses and sagebrush in sagebrush communities are particularly important to sage-grouse nest success. Tall grass cover in Oregon was greater at successful nests than at random sites or depredated nests and, except in one case, tall grasses at nondepredated nests consisted of residual cover (Gregg et al. 1994). DeLong et al. (1995) found odds of predation of simulated sage grouse nests in southeastern Oregon with 5\% tall grass cover and 29\% medium shrub cover (average cover for depredated nests [Gregg et al. 1994]) were 1.34 times greater than odds of predation of artificial nests with $18 \%$ tall grass cover and $41 \%$ medium shrub cover (average covers for nondepredated sage grouse nests). A study examining sage-grouse nest habitat selection and success across seven study areas in central and southwestern Wyoming reported that selected (compared to random sites) nest sites were located in areas with increased total shrub canopy cover, residual grass cover, and residual grass height compared to random sites and that successful nests had greater residual grass cover and grass height relative to unsuccessful nests (Holloran et al. 2005).

Our findings suggest ESDs could be refined to be more applicable to sage-grouse management. First, field measures for sage-grouse management using ESDs could include structural measures that are known to influence occurrence and success. ESD classifications do not adequately describe the occurrence of sagebrush, which is well known to be important for sagegrouse (Connelly et al. 2000; Hagen et al. 2007). ESD data describe the percent composition and production of plants and do not measure vegetative height, canopy cover, and other structural measures such as visual obstruction (Robel et al. 1970) that are known to influence sage-grouse nest site occurrence and success (Connelly et al. 2000; Hagen et al. 2007). Second, incorporating sage-grouse habitat ecology into a sage-grouse preference table may increase the utility of ESDs. Information on specific grass, forb, and shrub species known to benefit sage-grouse could better guide resource managers in determining sage-grouse index scores for sites having potential to support grouse. We show that composite values of local scale range information summarized by an SI score, while showing potential, were not adequate for management. Developing preference tables for individual plant species that evaluate their relative suitability as structural habitat characteristics or food sources used by sage-grouse for various life stages such as nesting may show future merit.

\section{IMPLICATIONS}

Our findings demonstrate that USDA-NRCS ESD databases would have to be refined to include relevant habitat measurements before they can be expected to accurately predict sagegrouse nest occurrence and success. Once specific habitat information is incorporated, ESDs should be tested across the sage-grouse range for their applicability to habitat conditions that support local grouse populations. Our analysis highlights that local scale habitat relationships and GIS based habitat selection models can refine USDA-NRCS prioritization of sagegrouse programs. The USDA-NRCS has already adopted using GIS based planning tools to deliver farm bill conservation programs for sage-grouse in core areas (e.g., Doherty et al. 2010b, 2011). Within core areas, discussions are underway to decide whether shrub canopy cover, shrub density, shrub height, nest shrub height, and visual obstruction metrics should be included in ESD data collection updates aimed at enhancing them for wildlife habitat management applications (W. Gilgert, USDA-NRCS, personal communication, July 2010). Grass height is not likely to be included in ESDs due to its high temporal and climatic variability; however, as indicated in our analysis, it is an important predictor that drives sage-grouse nest success. We therefore recommend grass height or an analogous measurement of grass stature be considered in future development of ESDs that direct rangeland management in areas with sage-grouse habitat.

\section{ACKNOWLEDGMENTS}

P. Gonzales, J. Kelly, and N. Lohse from the Natural Resources Conservation Service, and B. A. Jellison from the Wyoming Game and Fish Department, provided many useful insights. We thank J. D. Rodgers and W. C. Gilgert for comments to an earlier draft. J. W. Connelly and C. A. Hagen and provided constructive comments as manuscript reviewers.

\section{LITERATURE CITED}

AвbitT, R. J. F., J. M. Scott, AND D. S. Wilcove. 2000. The geography of vulnerability: incorporating species geography and human development patterns in conservation planning. Biological Conservation 96:169-175.

AldRidge, C. L., AND M. S. Boyce. 2007. Linking occurrence and fitness to persistence: a habitat-based approach for endangered greater sage-grouse. Ecological Applications 17:508-526

Balmford, A., J. L. Moore, T. Brooks, N. Burgess, L. A. Hansen, P. Williams, and C. Raнвек. 2001. Conservation conflicts across Africa. Science 291: 2616-2619.

BeYeR, H. L. 2004. Hawth's analysis tools for ArcGIS. Available at: http://www. spatialecology.com/htools. Accessed 15 May 2006.

Boyce, M. S., P. R. Vernier, S. E. Nielsen, and F. K. A. Schmiegelow. 2002. Evaluating resource selection functions. Ecological Modeling 157:281-300.

Brown, J. R., T. Svejcar, M. Brunson, J. Dobrowloski, E. Fredrickson, U. Krueter, K. Launchbaugh, J. Southworth, and T. Thurow. 2002. Range sites: Are they the appropriate spatial unit for measuring and managing rangelands? Rangelands 24(6):7-12.

Burnham, K. P., and D. R. Anderson. 2002. Model selection and multimodel inference: a practical information-theoretic approach. 2nd ed. New York, NY, USA: Springer-Verlag. $488 \mathrm{p}$.

Cagney, J., E. Bainter, B. Budd, T. Christiansen, V. Herren, M. Holloran, B. Rashford, M. Smith, AND J. WiLliams. 2010. Grazing influence, objective development, and management in Wyoming's greater sage-grouse habitat: with emphasis on nesting and early brood rearing. Laramie, WY, USA: University of Wyoming, Wyoming Experiment Station, Bulletin B-1203. 57 p.

Connelly, J. W., K. P. Reese, and M. A. Schroeder. 2003. Monitoring of greater sagegrouse habitats and populations. Moscow, ID, USA: University of Idaho, College of Natural Resources Experiment Station Bulletin 80. $47 \mathrm{p}$.

Connelly, J. W., M. A. Schroeder, A. R. Sands, and C. E. Braun. 2000. Guidelines to manage sage grouse populations and their habitats. Wildlife Society Bulletin 28:967-985

Delong, A. K., J. A. Crawford, and D. C. Delong, JR. 1995. Relationships between vegetational structure and predation of artificial sage grouse nests. Journal of Wildlife Management 59:88-92.

DOHERTY, K. E. 2008. Sage-grouse and energy development: integrating science with conservation planning to reduce impacts [dissertation]. Missoula, MT, USA: University of Montana. $125 \mathrm{p}$. 
Doherty, K. E., D. E. Naugle, H. E. Copeland, A. Pocewicz, and J. M. Kiesecker. 2011. Energy development and conservation tradeoffs: systematic planning for greater sage-grouse in their eastern range. In: S. T. Knick and J. W. Connelly [eds.]. Greater sage-grouse: ecology and conservation of a landscape species and its habitats. Studies in Avian Biology, volume 38. Berkeley, CA, USA: University of California Press. p. 505-516.

Doherty, K. E., D. E. Naugle, and B. L. Walker. 2010a. Greater sage-grouse nesting habitat: the importance of managing at multiple scales. Journal of Wildlife Management 74:1544-1553.

Doherty, K. E., J. D. Tack, J. S. Evans, and D. E. Naugle. 2010b. Mapping breeding densities of greater sage-grouse: a tool for range-wide conservation planning. Completion report to the Bureau of Land Management for Interagency Agreement No. L10PG00911. Washington, DC, USA: US Department of Interior-Bureau of Land Management. $29 \mathrm{p}$.

Giesen, K. M., T. J. Schoenberg, and C. E. Braun. 1982. Methods for trapping sage grouse in Colorado. Wildlife Society Bulletin 10:224-231.

Gregg, M. A., J. A. Crawford, M. S. Drut, and A. K. Delong. 1994. Vegetational cover and predation of sage grouse nests in Oregon. Journal of Wildlife Management 58:162-166.

Hagen, C. A., J. W. Connelly, and M. A. Schroeder. 2007. A meta-analysis of greater sage-grouse Centrocercus urophasianus nesting and brood-rearing habitats. Wildlife Biology 13(Supplement 1):42-50.

Herrick, J. E., B. T. Bestelmeyer, S. Archer, A. J. Tugel, and J. R. Brown. 2006. An integrated framework for science-based arid land management. Journal of Arid Environments 65:319-335.

Holloran, M. J., and S. H. Anderson. 2005. Spatial distribution of greater sagegrouse nests in relatively contiguous sagebrush habitats. Condor 107:742-752.

Holloran, M. J., B. J. Heath, A. G. Lyon, S. J. Slater, J. L. Kuipers, and S. H. Anderson. 2005. Greater sage-grouse nesting habitat selection and success in Wyoming. Journal of Wildlife Management 69:638-649.

Johnson, C. J., S. E. Nielsen, E. H. Merrill, T. L. Mcdonald, and M. S. Boyce. 2006. Resource selection functions based on use-availability data: theoretical motivation and evaluation methods. Journal of Wildlife Management 70:347-357.

Knick, S. T., D. S. Dobkin, J. T. Rotenberry, M. A. Schroeder, W. M. Vander Haegen, AND C. van Riper III. 2003. Teetering on the edge or too late? Conservation and research issues for avifauna of sagebrush habitats. Condor 105:611634.

Manly, B. F. J., L. L. Mcdonald, D. L. Thomas, T. L. Mcdonald, and W. P. Erickson. 2002. Resource selection by animals: statistical design and analysis for field studies. 2nd ed. Dordrecht, the Netherlands: Kluwer Academic. 221 p.

Robel, R. J., J. N. Briggs, A. D. Dayton, and L. C. Hulbert. 1970. Relationships between visual obstruction measurements and weight of grassland vegetation. Journal of Range Management 23:295-297.

StaTA. 2007. Stata version 10.0 reference manual. College Station, TX, USA: Stata Press. $608 \mathrm{p}$.

[USDA-NRCS] US Department of Agriculture, Natural Resources Conservation SERvice. 2006a. Land resource regions and major land resource areas of the United States, the Caribbean, and the Pacific Basin. Washington, DC, USA: USDA-NRCS, Handbook 296. 669 p.

USDA-NRCS. 2006b. National range and pasture handbook. Washington, DC, USA: USDA-NRCS, Handbook H_190_NRPH. Available at: http://directives.Sc. egov.usda.gov/viewDirective.aspx?hid=18937. Accessed 1 April 2011.

[USDI-FWS] USDI FISH AND WILDLIFE Service. 2010. Endangered and threatened wildlife and plants; 12-month findings for petitions to list the greater sagegrouse (Centrocercus urophasianus) as Threatened or Endangered; Proposed Rule. Federal Register 75:13909-13958.

Wakkinen, W. L., K. P. Reese, J. W. Connelly, and R. A. Fischer. 1992. An improved spotlighting technique for capturing sage grouse. Wildlife Society Bulletin 20:425-426.

Wallestad, R. O., and B. D. Pyrah. 1974. Movement and nesting of sage grouse females in central Montana. Journal of Wildlife Management 38:630-633.

Wilson, K., R. L. Pressey, A. Newton, M. Burgman, H. Possingham, and C. Weston. 2005. Measuring and incorporating vulnerability into conservation planning. Environmental Management 35:527-543. 